ISCKMC 2020

International Scientific Congress «KNOWLEDGE, MAN AND CIVILIZATION»

\title{
POPULATION AGING IMPACT ON EMPLOYMENT AND PENSION POLICY IN THE NORTH CAUCASUS
}

\author{
Shamil Magomedovich Gimbatov (a)*, Shihragim Kutaevich Kutaev (b), \\ Dmitrij Aleksandrovich Denevizyuk (c) \\ *Corresponding author
}

\begin{abstract}
(a) Institute of social economic researches of the Dagestan Federal Research Center RAS, 75 Yaragskogo str., Makhachkala, Russia, gimba@list.ru,

(b) Institute of social economic researches of the Dagestan Federal Research Center RAS, 75 Yaragskogo str., Makhachkala, Russia, kutaev.sh@mail.ru,

(c) Institute of social economic researches of the Dagestan Federal Research Center RAS, 75 Yaragskogo str., Makhachkala, Russia, deneviz@yandex.ru
\end{abstract}

\begin{abstract}
The presented study enables to assess the socio-demographic situation in the North Caucasian Federal District of Russia for more than a decade. A gradual change in the structure and reproduction of labor resources is observed on the territory of the North Caucasus of Russia. The region retains a relatively high proportion of the younger generation and able-bodied residents in the region amid a deteriorating economic situation, which produces tension in the labor market. However, the scale of outbound migration outside the regions of the most active part of the population is increasing. At the same time, there is a new tendency of reducing the part of youth in the region. One of the objectives of the study is to identify the patterns of socio-demographic dynamics and changes in the population structure in the North Caucasian Federal District of Russia in the context of existing problems regarding regional employment and their possible impact on the implementation of social policy and the economic situation in general. In our opinion, this will contribute to identifying the main directions of control and state regulation with regards to the ongoing changes in this area of the North Caucasus social development. The region, in our opinion, undergoes a structural shift in the reproduction of the population and labor resources leading to an increase in the proportion of the elderly population. In this connection, there is a need for an institutional revision of the priority areas of regional demographic and social policy.
\end{abstract}




\section{Introduction}

In our opinion, the peculiarities of forming the demographic and human potential of the population living in the North Caucasus largely determine both the regional features of labor resources and labor markets formation, and the nature of forming social and economic processes in the region in general.

Against the background of a decrease in the indicators of natural population growth in the territories of the North Caucasus of the Russian Federation, there is a change in the structure of the labor resources reproduction, a decrease in the working population, an increase in the part of the elderly population. In these conditions, the problem of population aging is becoming urgent, despite the relatively favorable demographic situation in comparison with other regions of Russia. Population aging is a global phenomenon marked by spatial differences between developed and developing countries. Population aging is a relatively recent phenomenon in most countries. The population aged 60 is projected to rise from 962 to 2.1 billion by 2050, with developing countries experiencing $80 \%$ of this growth (Rishworth \& Elliott, 2020). The Russian Federation is no exception. Russian population is aging and reducing while fertility rates are falling and the number of poor people is growing.

At the same time, in the North Caucasus, there is still a high proportion of the younger generation among the population of working age. The number of people under working age in some republics of the North Caucasus reaches $30 \%$ (despite the fact that the all-Russian level is only $18 \%$ ). Against the background of the deterioration of the general economic situation, there is an increase both in tension on the labor market and in the scale of migration outside the regions having the most active part of the population. Over the past decades, there has been a significant migration decline in the population (in 2018 it amounted to $-11,008$ people, and over the past 10 years to $-13,000$ people on average annually). There is a close relationship between demographic, migration and employment processes. Currently, the workforce in the Russian Federation is more than 76 million people, and in the North Caucasus Federal District it is 4.6 million. Among the regions of the North Caucasus Federal District, 1.3 million people are in the Republic of Dagestan and the Stavropol Territory. The total labor force in the rest of the constituent entities of the federal district is 1.8 million people.

Considering the situation in the field of employment, it should be noted that in the North Caucasus Federal District the largest number of the employed in absolute terms is observed in the Stavropol Territory and the Republic of Dagestan being 1.2 and 1.1 million people, respectively. At the same time, the unemployment rate in Dagestan is extremely high and is equal to $11 \%$. A positive trend for the analyzed period is shown by most of the subjects with the exception of Karachay-Cherkessia and North Ossetia-Alania, where there was a slight decrease in this indicator.

\section{Problem Statement}

The relatively difficult social situation in the region described above, specifically, the uncertainty of the employment situation, increased migration with a high level of potential labor force, especially among young people of working age creates an ambiguous socio-demographic situation, which has been contributing to the strengthening a still implicit but objective trend of gradual population aging over the past twenty years. Let us note, at the same time, that this process is not so noticeable and relevant in the 
agenda of regional social policy on the territory of the subjects of the North Caucasus Federal District yet. The adverse economic consequences of aging workforce are characterized by the reduction in the average number of working years of a population that spends most of their youth unemployed (Manton, 2008).

Although the emerging demographic situation is not yet obvious and not particularly pronounced in comparison with other regions of Russia, the rate of change in the population structure indicates a generating shift in the age structure of the population towards an increase in the proportion of the elderly people in the North Caucasus. Moreover, the number of the population above the working age has been growing in the territories of the North Caucasus Federal District at a higher rate than the average indicators for Russia over the past twenty years. If the growth rate of the elderly population in the country increased by 7 percentage points, then in the North Caucasus Federal District it increased by $30 \%$ from 2010 to 2018 compared with an earlier decade. Thus, the process of population aging, which is observed in almost all regions of the country, may well become an objective reality in the Caucasus region in the near future.

\section{Research Questions}

Studying trends in the sociodemographic situation and their impact on the implementation of social policy includes the following:

1. Studying the qualitative dynamics of changes in the structure of the population in the context of ages and the identification of factors that most strongly affect the formation of the transformation process of the socio-demographic structure of the population in the North Caucasian regions of Russia.

2. Research of changes in the socio-demographic structure of the population in the context of existing problems in the field of regional employment and problems of pension provision in the territories of the North Caucasus Federal District.

\section{Purpose of the Study}

To determine the consistency of the dynamics of socio-demographic processes in the region and highlight the main areas of control regarding the ongoing changes in this area of social development of the North Caucasian Federal District of Russia.

\section{Research Methods}

In the scope of the topic of this article, the change in the population structure is seen more clearly through the calculation of the coefficient of the retirement burden. It is expressed in relation to the number of the population of the "pre-working" age to the number of the population of retirement age (formula 1). In the case of the dynamics of the retirement load, the decline in the trend in Figure 1 indicates a decrease in the population at a young age in relation to citizens in old age as evidenced by a decreasing trend, especially clearly expressed in the example of the Republic of Dagestan (Gimbatov et al., 2018). 
This indicator is expressed through the calculation of the ratio of young people in the so-called "pre-working" age to the number of older working age.

Aged dependency ratio is calculated using the following formulas:

$$
\begin{aligned}
K \text { pw } & =\mathrm{S} \text { pa } / \mathrm{S} \text { wa } \\
\mathrm{K} \text { pd} & =\mathrm{S} \text { pa } / \mathrm{S} \text { da }
\end{aligned}
$$

where, $\mathrm{S}$ pa is the retirement age population (age from 60 years and above).

$\mathrm{S}$ da is the population of "pre-working" age (age from 0 to 15 years old);

$\mathrm{S}$ wa is working age population (working age (age from 0 to 15 years 15 to 59 years old));

The results of calculating the coefficients for the period since 2000 are shown in the graphs in Figure 1.
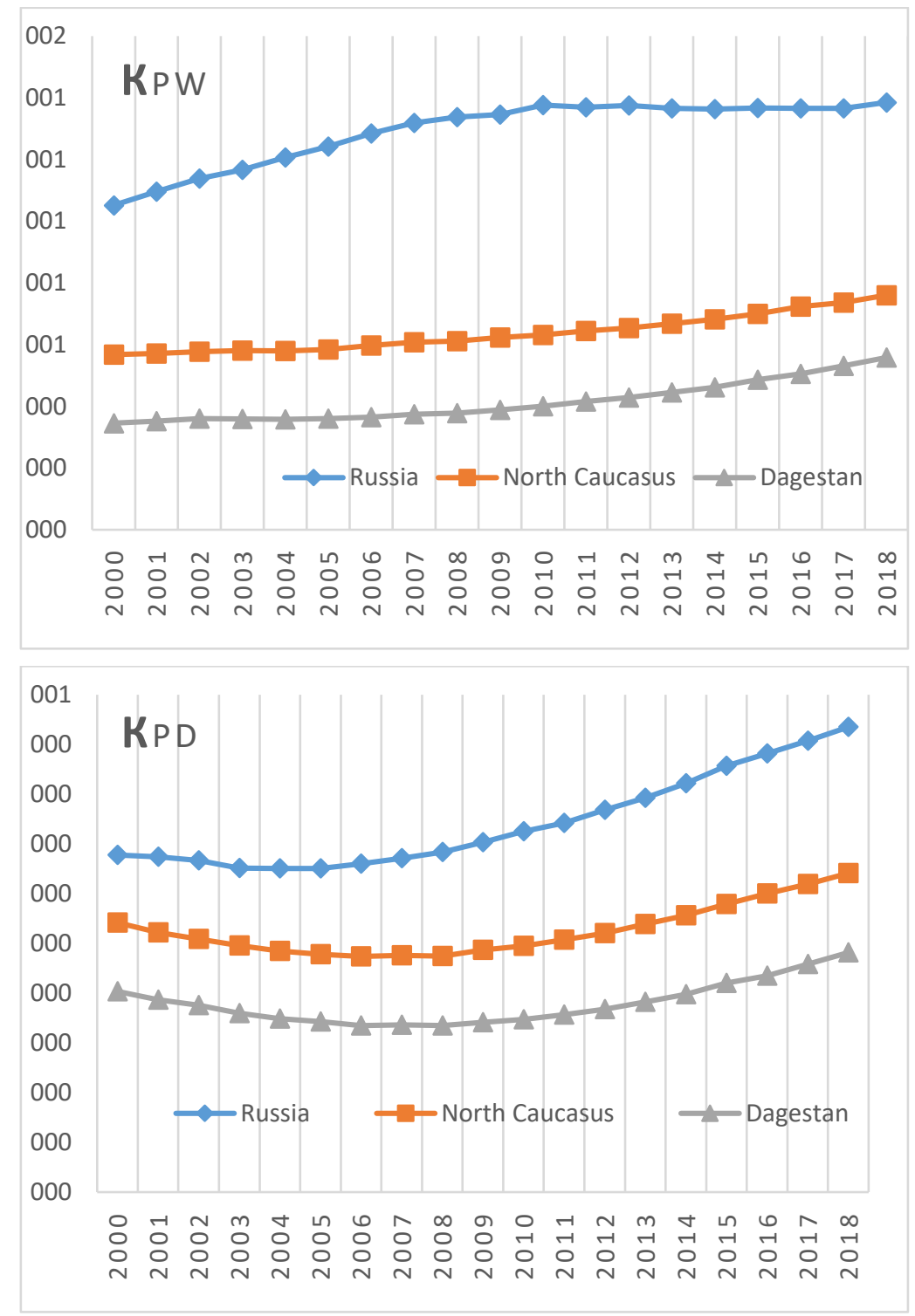

Figure 1. Replacement rates of labor resources [calculated by the author] 
Figure 2 below shows the characteristics of changes in the demographic load calculated using the formula $\mathrm{Kd}=\mathrm{Spa}+\mathrm{Sda} / \mathrm{Swa}$, which expresses the ratio of the number of enlarged age groups being children (0-14 years old), elderly and old people (60 years old and older), able-bodied (conditionally 15-59 years), showing the load on society by the unproductive population (Efimova et al., 2011).

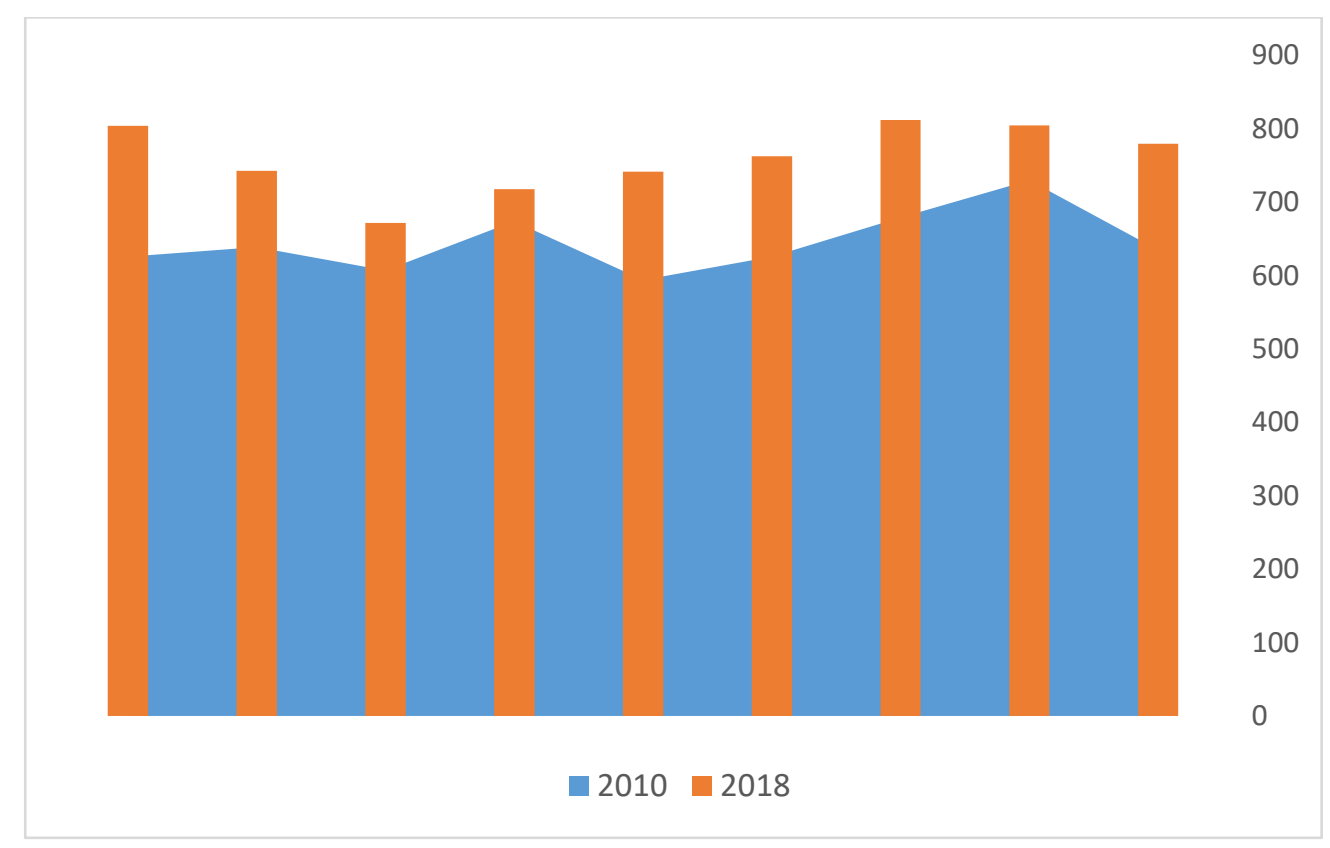

Figure 2. Dependency ratio in the Republic of Dagestan calculated by the author and based on the data (GosKomStat, 2019)

\section{Findings}

In general, in the North Caucasus and, in the Republic of Dagestan, in particular, we witness coefficients equalization (potential replacement and pension burden) in relation to the average Russian dynamics (Figure 1). At the same time, with regards to the coefficient of potential replacement of labor resources, the level of the indicator according to the results of the last three years practically does not differ from the national average.

The tendency of changes in the socio-demographic structure of the population is mainly formed due to a decrease in the "pre-working" age population and an increase in the number of citizens of senior working and retirement age. The aging process that most regions of Russia have faced is gradually beginning to transform the demographic structure of the population and the reproductive potential of the North Caucasus.

At the same time, there is an increase in the level of participation of the population of the age groups 15-19 and 60-72 in the labor force in the Republic of Dagestan being the most numerous region of the North Caucasus Federal District. This suggests that the young of Dagestan at the age of 15-19 continue to work or are actively looking for work instead of receiving an education and people aged 60-72 work after retirement. At the same time, here the demographic load on people of working age is 
the most pronounced. In general, the burden of the population at retirement and "pre-working" age on the able-bodied population is growing, which in the near future will require a revision of the measures in pension policy field.

In our opinion, the main reasons for the decline in the younger generation and the increase in the number of the older age population in the North Caucasus are as follows:

1) The fall in the birth rate, the demographic pitfalls of the nineties of the last century. The demographic crisis of the nineties did not bypass the Caucasian republics either. During that period, there was a rather sharp decline in fertility rates from $14 \%$ in the mid-90s and to $11.2 \%$ by the end of the twentieth century.

2) The lower standard of living in the post-crisis decade. Since 2008 (the decline in the standard of living in 2009 was almost twice the national average (Kudrin, 2018) and he most pronounced one after 2014 (RF Government, 2017)

3) Migration processes activation in the North Caucasus including urbanization. A decrease in the part of the rural population, the formation of large agglomerations, pulling together the population of rural areas as well as labor migration outside the places of permanent residence, often irreversible migration of the population, increased educational migration (Gimbatov, 2008). As a result of intensive migration, changes are taking place in the age and sex structure of the population both in those regions where people leave in and the ones where the influx of migrants prevails.

4) One of the consequences of the decrease in the number of young people starting from 2000 was a gradual decrease in the birth rate of the population in the North Caucasus Federal District for the observed period starting from 2010. For example, according to the results of the 2002 National Population Census in the Republic of Dagestan, about $60 \%$ of the population was under 30 years of age. By 2016, the part of young people in this age category had decreased by almost $10 \%$ and now amounts to $51 \%$. At the same time, since 2010 the number of women of reproductive age has decreased by almost $4 \%$ in general, and by $6 \%$ in the age group 15-29 years old (GosKomStat, 2019).

\section{Conclusion}

In our opinion, at the background of the relatively favorable demographic situation, there are relatively contradictory demographic trends that require the implementation of a balanced and effective government policy aimed at sustainable development of the social sphere of the region. It is necessary to restructure the institutional mechanisms for social policy implementation.

Under these conditions, the issue of developing the pension sphere in the region becomes urgent, which will certainly be determined by both the demographic aging of the population and the situation on the labor market. Additional measures of social policy should be the ones for the development of additional pension provision; stimulating the formation of voluntary savings for old age and increasing financial literacy; increasing labor productivity of the elderly population of the country; expanding the forms of social and economic activity of the elderly. The influence of different socio-economic factors on various groups of the population indicates the need for differentiated policies regarding the age and social heterogeneity of the elderly population (Wang, 2020). 
In this vein, we consider the measures aimed to raise the retirement age to be less effective, since in this case the solution to the problem occurs exclusively due to a mechanical change in the age structure, i.e. by simply transferring part of the population above the working age category to the working age one. At the same time, changes in improving productivity efficiency remain indefinitely delayed. Thus, the main result can and should be the measures in the field of economic and labor market policies.

It is possible to solve the problem of increasing the income part of the pension system in the conditions of a gradual increase in the demographic burden on the able-bodied population by "whitewashing" the informal sector of the economy, which, in our opinion, is the most inappropriate.

The problem of the growing burden on the pension system is superimposed on the problem of shady employment as a factor that reduces the volume of pension contributions. The processes of shady employment are especially pronounced in the republics of the North Caucasus Federal District, where the issue of accounting for those employed in the economy is especially acute.

Official statistics registered the scale of informal employment in 2017, according to which its level in the North Caucasus Federal District and Dagestan amounted to $44.9 \%$ and $56 \%$, respectively, while the average indicator for Russia is $19.8 \%$.

$45 \%$ out of 5,000 participants of a survey conducted by the Ministry of Labor and Social Development of the Republic of Dagestan stated that they worked without signing an employment contract, and the number of those who received an unofficial salary was $46.4 \%$. The analysis of the employed at their main place of work revealed that more than $54.9 \%$ of those employed in the Republic of Dagestan worked in their own households in the sphere of entrepreneurial activity without forming a legal entity by being hired by individuals, individual entrepreneurs, in the farm. However, $56.1 \%$ of employees in Russia and $81.6 \%$ employees in the North Caucasus work in enterprises with the status of legal entities. More than half of those employed in the economy work unofficially or hide part of their wages from insurance premiums, thereby using the so-called "gray" schemes" (Akhmeduev \& Ilyashenko, 2017).

As we can see, the process of demographic potential formation in the regions of the North Caucasus largely determines both the features of the labor market process formation as a whole, and the nature of social processes that have developed in the region.

One of the reasons for the current relatively difficult employment situation in the region is the ineffective use of the demographic and labor potential of the population, including the younger generation living in the North Caucasian Federal District. That is why, a necessary condition of the effective state social policy formation and implementation in the North Caucasus Federal District is concerning the peculiarities of socio-demographic processes and transformations of the demographic behavior of the population, which has taken place in recent years, including changes in reproductive and migratory behavior, with regards to their impact on the formation of social -economic problems.

\section{References}

Akhmeduev, A. S., \& Ilyashenko, S. V. (2017). Shadow economy of Dagestan: problems and ways of legalization. Reg. probl. of econ. transform., 1, 120-127. https://www.elibrary.ru/item .asp? id = 18967283 
Efimova, M. R., Petrova, E. V., \& Rumyantsev, V. N. (2011). General theory of statistics. Textbook. Infra-M.

Gimbatov, S. M., Kutayev, S. K., \& Gichiyev, N. S. (2018). Social And Demographic Aspects Of Region-al Labor Market Development. The European Proceedings of Social \& Behavioural Sciences, 58, 2032-2038. https://doi.org/10.15405/epsbs.2019.03.02.236

Gimbatov, S. M. (2008). Modern trends in seasonal work in the Republic of Dagestan. Quest. of structur. the econ., 2, 167-172. https://www.elibrary.ru/item.asp?id=16535825

GosKomStat (2019). Demographic Yearbook of Russia. https://www.gks.ru/storage/mediabank/Dem_ejegod-2019.pdf

Kudrin, A. L. (2018). How the Russian economy survived the 2008 crisis, RBC-Daily. https://www.rbc.ru/newspaper/2018/09/18/5b9f6cca9a794709e69e13c5

Manton, K. G. (2008). Population and labor force aging, effect on socio-economic development in brazil, russia, india and china. In International Encyclopedia of Public Health (pp. 170-181). Elsevier Inc. https://doi.org/10.1016/B978-012373960-5.00556-6

RF Government (2017). Social Bulletin. Russ. Government. https://ac.gov.ru/files/publication/a/14616.pdf

Rishworth, A., \& Elliott, S. J. (2020). Aging in the Developing World. In International Encyclopedia of Human Geography (pp. 79-82). Elsevier. https://doi.org/10.1016/b978-0-08-102295-5.10361-0

Wang, S. (2020). Spatial patterns and social-economic influential factors of population aging: A global assessment from 1990 to 2010. Social Science and Medicine, 253, 112963. https://doi.org/10.1016/j.socscimed.2020.112963 